\title{
The body mass index (BMI) as a public health tool to predict metabolic syndrome
}

\author{
Miguel Murguía-Romero ${ }^{1}$, Rafael Jiménez-Flores ${ }^{2}$, Rafael Villalobos-Molina ${ }^{1,3}$, \\ María Isabel Mendoza-Ramos ${ }^{2}$, Julia Reyes-Reali ${ }^{2}$, Santiago C. Sigrist-Flores ${ }^{4}$, \\ Adolfo René Méndez-Cruz ${ }^{2 *}$ \\ ${ }^{1}$ Unidad de Biomedicina, FES Iztacala, UNAM, Tlalnepantla, México \\ ${ }^{2}$ Carrera de Médico Cirujano, FES Iztacala, UNAM, Tlalnepantla, México; ${ }^{*}$ Corresponding Author: renemen@gmail.com \\ ${ }^{3}$ Carrera de Enfermería, FES Iztacala, UNAM, Tlalnepantla, México \\ ${ }^{4}$ Posgrado en Ciencias Biológicas, FES Iztacala, UNAM, Tlalnepantla, México
}

Received 6 October 2011; revised 15 November 2011; accepted 12 December 2011

\section{ABSTRACT}

Objective: To analyze the body mass index (BMI) as an indicator of metabolic alterations, including the metabolic syndrome (MetS), at both individual level and public health level. Method: We recruited 3683 undergraduate students (17 - 24 years old) from México City identifying metabolic alterations, including the MetS, and comparing its prevalence by BMI ranges. We applied a sensitivity analysis to define BMI optimal cut-off point values. Results: We found $14.6 \%$ of MetS prevalence with a BMI average of $24.2 \%$, and $34.5 \%$ of overweight prevalence (BMI $\geq 25$ ). A BMI cut-off point value of 22.5 is suggested as an upper limit of a normal weight condition, only for public health purpose; while at individual level the BMI cut-off point of 25 was corroborated as the upper limit for a normal weight condition. A public health tool to estimate the MetS prevalence based on BMI percentages is proposed, and a study case is presented. Conclusion: BMI fails predicting at individual level both, healthy condition or metabolic alterations, when values are lower than 25 . At population level, the $\mathrm{BMI}$ is a valuable public health tool to estimate MetS prevalence: based on the prevalence of MetS by BMI ranges of a sample of the population.

Keywords: BMI; Metabolic Syndrome; Obesity; Public Health Tool

\section{INTRODUCTION}

The body mass index (BMI) is a widely used tool to evaluate overweight and obesity based on two anthropometric parameters, height and weight:

$$
\mathrm{BMI}=\text { weight } / h^{2} i g h t^{2}
$$

where weight is measured in kilograms, and height in meters.

The World Health Organization (WHO) has emitted recommendations on the reference values (cut-off points), to classify the weight condition of a person (underweight, normal, and overweight). Although some differences in the values of normal ranges for different populations has been recognized by WHO, however arguing compatibility [1], this agency recommends a universal classification of BMI values through a set of cut-off points to classify the weight conditions: $<18.5$ Underweight; $18.5-<25.0$ Normal weight; $\geq 25.0$ Overweight $[2,3]$. These universal cut-off points for BMI are based on the probability to acquire diabetes and of mortality [2,4], but it is known that diabetes is only a possible consequence, among many other disorders, associated to obesity, which has increased its prevalence worldwide among young population in recent years, and it has been recognized as epidemic in almost all countries [5-8].

Obesity can be seen as a particular case, stage, or component, of the metabolic syndrome (MetS), and could be better understood when it is analyzed as a component and in some cases, as a consequence of the syndrome. The routes leading to MetS, a multifactorial process, could involve positive and negative feedback between its components. Thus, it is suitable to expect a wide range of combinations of alterations among individuals with MetS, and also in overweighed individuals too (assessed by BMI). That expectation, applied to BMI ranges, could be translated to find individuals with metabolic alteration at both sides of the BMI cut-off point of 25 . Then the questions are: which is the relative frequency of individuals with metabolic alterations along BMI values? Is 25 an adequate BMI cutoff point for the age range of young Mexicans? Is there a BMI value under 25 that better differentiates the normal weight from overweight conditions for this population? 
In order to have BMI as a more precise indicator of metabolic alterations, it is relevant to assess the sensitivity of BMI reference values [2] in healthy and not healthy conditions for diverse population groups, such as young Mexicans. We hypothesized that BMI of a healthy population shows a normal distribution, i.e., the frequency of BMI values grouped by ranges conforms a bell-shaped curve. That implies that some BMI values are higher than others, both belonging to healthy persons.

If the next five conditions are taken into account to define BMI cut-off points, it could make BMI a more efficient tool in health promotion:

1) BMI should include in the analysis a criteria to classify persons into "healthy"/"not healthy", and not to support the decisions only on percentile curves.

2) BMI should use a wider inclusive health definition, wider than the absence of diabetes or hypertension, by instance, alterations related to MetS.

3) BMI should consider specific populations, including factors as age, gender, and geographic or ethnic origin.

4) BMI should report explicitly the probabilities of being healthy (or not healthy) by each class of BMI ranges.

5) BMI should subdivide its ranges according to the elasticity of probabilities of being healthy.

We propose that there is a percentage of the population with a BMI lower than 25 (the upper cut-off point for "normal weight" range as recommended by WHO), which present metabolic disorders. We conceptualize the BMI scenario as having a fuzzy limits that made the 25 cut-off point only an upper threshold of "normal weight".

If an operational definition of healthy condition is used to establish BMI cut-off points, this tool could detect more efficiently early adverse consequences of obesity for young population's health. In this regard MetS would bring a more comprehensive/inclusive frame to define the cut-off points for BMI ranges, than diabetes or mortality probabilities do. If those cut-off points are adjusted to the probability of acquire obesity-related metabolic disorders, such as those associated with MetS, it will be a more efficient tool to differentiate between healthy and not healthy stages. The analysis and definition of BMI reference values for specific populations yield more accuracy to the index. For example, by defining reference values for age and sex groups, BMI would detect more precisely the obesity classes [9]. In that respect, WHO recommends BMI cut-off points for boys and girls from 0 to 5 years of age [10]. That recommendation is based on a percentile definition perspective, i.e., WHO reports BMI values at 3, 15, 50, 85, and 97 percentiles, but their relation with children's healthy/not healthy conditions is not clear. Some studies used only percentile curves to define BMI cut-off points without assessing at least one healthy condition [9]. Ezzati et al., proposed a universal cut-off point of $21 \mathrm{~kg} / \mathrm{m}^{2}$ based on the risk of several health related problems [11]; in con- trast, we propose that BMI cut-off point needs to be related to a more particular set of diseases, i.e., MetS, in order to made BMI a more accurate predictor of healthy problems.

The objective of this study was to define specific BMI reference values (cut-off points) for young Mexicans (ages 17 - 24 years), based on a healthy/not healthy operational definition that could help detecting metabolic disorders, as early stages of MetS. To make BMI a more precise and accurate tool, we propose a subdivision of BMI ranges while reporting the probabilities of being healthy and to have MetS. Also, we want to bring a tool that estimates MetS prevalence in a population based on probabilities by BMI ranges; we give an example to estimate MetS prevalence by State in México.

\section{METHODS}

\subsection{Participants}

A total of 3683 undergraduate students, aged $17-24$ years, participated in a project to evaluate the health of young Mexicans, from years 2008 to 2010. All students signed an informed consent. Blood samples were taken, also anthropometry was measured (waist circumference, blood pressure, height and weight) and collected for each student. Blood samples were analyzed by CARPERMOR S.A. de C.V., an international reference laboratory to obtain blood chemical parameters.

\subsection{BMI Calculation for Healthy and Not Healthy Students}

BMI was calculated with the well known formula:

$$
\mathrm{BMI}=\text { weight } / \text { height }^{2}
$$

where weight is measured in kilograms, and height in meters. Those 3683 students were classified in two subsamples: "healthy" students and "not healthy" students, dependent if the student bears or not a metabolic alteration; in this study we considered metabolic alterations as those reported by Alberti et al., that define MetS (Table 1) [12], which is pretty similar to the American Heart Association

Table 1. Reference values of clinical and anthropometric parameters to define the metabolic syndrome [12].

\begin{tabular}{ll}
\hline Parameter & Categorical cut-off point \\
\hline HDL Cholesterol & $<50 \mathrm{mg} / \mathrm{dL}$ in women \\
& $<40 \mathrm{mg} / \mathrm{dL}$ in men \\
& $\geq 80 \mathrm{~cm}$ in women \\
Waist circumference & $\geq 90 \mathrm{~cm} \mathrm{in} \mathrm{men}$ \\
Triglycerides & $\geq 150 \mathrm{mg} / \mathrm{dL}$ \\
Blood pressure & $\geq 130 \mathrm{mmHg}$ systolic \\
Fasting glucose & $\geq 85 \mathrm{mmHg}$ diastolic \\
\hline
\end{tabular}


(AHA) definition [13]. Also, a subsample showing MetS was defined as the set of such students with three or more metabolic alterations. This MetS set was a subsample of the "not healthy" students group.

\subsection{BMI Statistics of the Sample}

Frequency histograms by WHO BMI ranges and by unit of BMI value $\left(16-17 \mathrm{~kg} / \mathrm{m}^{2}, 17-18 \mathrm{~kg} / \mathrm{m}^{2}\right.$, etc.) were built, obtaining the basic statistics, mean and standard deviation. Both, the whole sample and the healthy subsample, were plotted in the same graph to visually exploring it.

\subsection{Probabilities of Being "Healthy"/"Not Healthy", "with MetS" by BMI Ranges}

For each range of BMI, and for both ranges schemes (by WHO BMI ranges, and by BMI unit ranges), the proportions of "healthy" and "not healthy" students were calculated. These proportions are reported as the probabilities of being healthy/not healthy at each BMI range.

\subsection{Cut-Off Points}

The cut-off points for BMI were defined using two approaches: 1) percentiles: by defining the BMI values dependent on which proportion of the population is below and above of them, and 2) sensitivity analysis: by classifying as healthy/not healthy condition, and searching for a proportion that minimizes the committed and omitted errors.

\subsection{Defining Cut-Off Points Based on Percentiles}

The cut-off points setting based on percentiles could be used as threshold values. The BMI value at the $95 \%$ cumulated frequency of the healthy sample, could represent an upper BMI value for the normal weight class. If the cumulated frequencies of "not healthy" students are calculated downward, then the $95 \%$ could be used as a lower threshold for an inadequate weight. If both subpopulations, "healthy" and "not healthy", show a normal distribution, and if both curves are overlapped, then those lower and upper thresholds could be far away, showing an overlapped region where both healthy and not healthy coexist.

\subsection{Defining Cut-Off Point Based on Sensitivity Analysis}

This definition is quite similar to that of percentiles, i.e., if both cumulated curves of "healthy" and "not healthy" cases are plotted (the second one calculated in reverse order), then the point where both curves cross, represents the optimum cut-off point that detects the same proportions of "healthy" and "not healthy" cases. That point minimizes both types of errors, committed and omitted. Any other point will displace the error to some of the two classes.

\subsection{Estimating MetS Prevalence in México}

We applied the found proportions of MetS by WHO BMI range to a public health survey [14], in order to estimate the population (17 - 24 years old) with MetS in México: the proportions were multiplied by the Mexican total population of 17 - 24 years old. To estimate the Mexican population of the target age range, we used the data by México's States obtained from the national population census [15], and from a public sample data of about $10 \%$ of the total records [16]. As the available public data report the population in the year 2005, we also applied a mortality rate to estimate the young population at year 2010 [17].

\section{RESULTS}

\subsection{The "Not Healthy" Cases within the BMI "Normal Weight" Class}

For the analyzed sample it was a considerable proportion of "not healthy" cases with a BMI value in the "normal weight" class (from 18.5 to less than 25 ). Only $38 \%$ of students with a BMI value in the "normal weight" class are "healthy" (Table 2), which suggests that the 25 $\mathrm{kg} / \mathrm{m}^{2}$ upper limit for the normal weight class needs to be revised (for short in the next paragraphs we omitted the units, $\mathrm{kg} / \mathrm{m}^{2}$, for BMI values).

Table 2. Health statistics according to BMI (probabilities of being "healthy", "with 1 or 2 alterations", and "with MetS" by WHO BMI range).

\begin{tabular}{lccccccc}
\hline \multicolumn{1}{c}{ Students } & All & Underweight & Normal weight & Overweight & $\begin{array}{c}\text { BMI } \\
(\text { mean } \pm \text { SD) }\end{array}$ & $\begin{array}{c}\text { mean } \pm 1 \cdot \text { SD } \\
(68 \%)\end{array}$ & $\begin{array}{c}\text { mean } \pm 2 \cdot \text { SD } \\
(95 \%)\end{array}$ \\
\hline All & $3683(100.00 \%)$ & $102(100.00 \%)$ & $2312(100.00 \%)$ & $1269(100.00 \%)$ & $24.2 \pm 4.3$ & $(20.0-28.5)$ & $(15.7-32.7)$ \\
"Healthy" & $1021(27.7 \%)$ & $62(60.8 \%)$ & $879(38.0 \%)$ & $80(6.3 \%)$ & $21.6 \pm 2.4$ & $(19.2-24.0)$ & $(16.8-26.4)$ \\
"With 1 o 2 alterations" & $2124(57.8 \%)$ & $38(37.2 \%)$ & $1,319(57.1 \%)$ & $767(60.4 \%)$ & $24.3 \pm 3.9$ & $(20.5-28.2)$ & $(16.6-32.1)$ \\
"With MS" & $538(14.6 \%)^{\mathrm{a}}$ & $2(2.0 \%)$ & $114(4.9 \%)$ & $422(33.3 \%)$ & $28.7 \pm 4.6$ & $(24.1-33.2)$ & $(19.5-37.8)$ \\
\hline
\end{tabular}

${ }^{\mathrm{a}}$ Here is shown that MetS prevalence in the sample is $14.6 \%$. 


\subsection{BMI Statistics of the Sample}

BMI average for all the sample was $24.2(\mathrm{SD}=4.3$; Table 2). Disaggregating the sample by healthy condition, BMI averages were 21.6 ( $\mathrm{SD}=2.4), 24.3(\mathrm{SD}=3.9)$, and $28.7(\mathrm{SD}=4.6)$ for the "healthy", "not healthy" with 1 or 2 alterations, and "not healthy" with MetS, respectively.

\subsection{Probabilities of Being "Healthy"/"with 1 or 2 Alterations"/“with MetS" by BMI Class}

The sample studied showed a MetS prevalence of $14.6 \%$ (Table 2); while 1/3 of the "overweight" WHO BMI range presented MetS (33.3\%), MetS prevalence in the other two classes is considerably lower $(2.0 \%$ in underweight; $4.9 \%$ in normal weight; Table 2). The prevalence of students with 1 or 2 metabolic alterations is very high in all three WHO BMI ranges: $37.2 \%$ in underweight; $57.1 \%$ in normal weight, and $60.4 \%$ in overweight. The percentages of students without alterations (healthy students) vary across the three BMI ranges, with only $38.0 \%$ in the "normal weight" class (Table 2). The probabilities of being healthy calculated by ranges of BMI unit (Figure 1 and Table 3) decrease with larger BMI, it shows a linear shape from $78.9 \%$ at $16-17$ class, to $0 \%$ at $29-30$ class. The probability of having 1 or 2 metabolic alterations ranges from $40 \%$ to $70 \%$ in any class. The probabilities to bear MetS increase linearly from $0 \%$ at the $18-19$ class, to $63.6 \%$ at $34-35$ class.

\subsection{Cut-Off Points}

The percentile analysis to define the cut-off points shows that $95 \%$ of the healthy population has a BMI lower than
25 (Table 4), and that 95\% of the "not healthy" population has a BMI higher than 19. So, it is plausible to define BMI upper limit as 25 for "normal weight" related to metabolic alteration (including MetS).

The sensitivity analysis to define the cut-off points shows an optimum point at 22.5 , detecting correctly $73.8 \%$ of

Table 3. Probabilities of being "healthy", "with 1 or 2 alterations" or "with MetS" by BMI unit range (Mexicans, 17 - 24 years old).

\begin{tabular}{|c|c|c|c|c|}
\hline $\begin{array}{l}\text { BMI class } \\
\text { by unit }\end{array}$ & Total & "Healthy" & $\begin{array}{c}\text { "With } 1 \text { or } \\
2 \text { altera- } \\
\text { tions" }\end{array}$ & $\begin{array}{l}\text { "With } \\
\text { MetS" }\end{array}$ \\
\hline 16 & $100.0 \%$ & $78.9 \%$ & $21.1 \%$ & $0.0 \%$ \\
\hline 17 & $100.0 \%$ & $59.2 \%$ & $39.5 \%$ & $1.3 \%$ \\
\hline 18 & $100.0 \%$ & $55.4 \%$ & $44.6 \%$ & $0.0 \%$ \\
\hline 19 & $100.0 \%$ & $50.4 \%$ & $47.6 \%$ & $2.0 \%$ \\
\hline 20 & $100.0 \%$ & $47.3 \%$ & $50.6 \%$ & $2.1 \%$ \\
\hline 21 & $100.0 \%$ & $41.3 \%$ & $56.3 \%$ & $2.5 \%$ \\
\hline 22 & $100.0 \%$ & $37.9 \%$ & $57.5 \%$ & $4.7 \%$ \\
\hline 23 & $100.0 \%$ & $28.5 \%$ & $64.8 \%$ & $6.7 \%$ \\
\hline 24 & $100.0 \%$ & $21.2 \%$ & $66.2 \%$ & $12.6 \%$ \\
\hline 25 & $100.0 \%$ & $16.3 \%$ & $70.0 \%$ & $13.8 \%$ \\
\hline 26 & $100.0 \%$ & $10.9 \%$ & $60.2 \%$ & $28.9 \%$ \\
\hline 27 & $100.0 \%$ & $5.8 \%$ & $70.5 \%$ & $23.7 \%$ \\
\hline 28 & $100.0 \%$ & $3.1 \%$ & $64.1 \%$ & $32.8 \%$ \\
\hline 29 & $100.0 \%$ & $0.0 \%$ & $58.7 \%$ & $41.3 \%$ \\
\hline 30 & $100.0 \%$ & $1.9 \%$ & $54.7 \%$ & $43.4 \%$ \\
\hline 31 & $100.0 \%$ & $0.0 \%$ & $48.5 \%$ & $51.5 \%$ \\
\hline 32 & $100.0 \%$ & $0.0 \%$ & $55.9 \%$ & $44.1 \%$ \\
\hline 33 & $100.0 \%$ & $2.1 \%$ & $41.7 \%$ & $56.3 \%$ \\
\hline 34 & $100.0 \%$ & $0.0 \%$ & $36.4 \%$ & $63.6 \%$ \\
\hline 35 & $100.0 \%$ & $0.0 \%$ & $44.4 \%$ & $55.6 \%$ \\
\hline 36 & $100.0 \%$ & $0.0 \%$ & $44.4 \%$ & $55.6 \%$ \\
\hline 37 & $100.0 \%$ & $0.0 \%$ & $45.5 \%$ & $54.5 \%$ \\
\hline
\end{tabular}

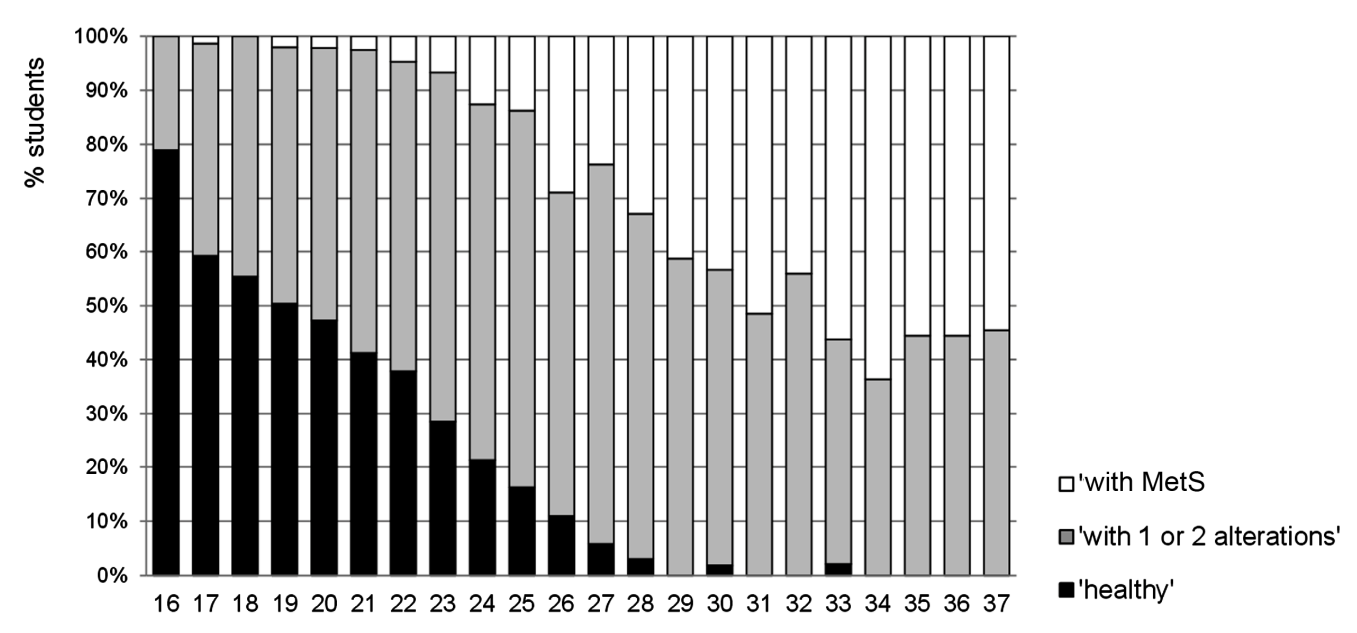

BMI

Figure 1. Relative frequency of students grouped into three health conditions according to BMI. Notice that students with a BMI value above 25 are mainly not healthy (either with MetS or with 1 or 2 metabolic alterations), and students with a BMI value below 25 include both, healthy and not healthy. The only BMI classes that include more than $50 \%$ of healthy students are 16, 17, 18 and 19. 
"healthy" population, and $70.6 \%$ of "not healthy" population (Figure 2 and Table 4), i.e., 73.8\% of "healthy" students have a BMI lower than 22.5, and $70.6 \%$ of "not healthy" students have a BMI higher than 22.5.

\subsection{Estimating MetS Prevalence in México}

Metabolic Syndrome prevalence estimation based on BMI ranges was $15.94 \%$ for the whole country, varying from $14.19 \%$ in Chiapas State to $18.22 \%$ in Quintana Roo State (Figure 3 and Table 5). The State of México, and those States from Peninsula of Yucatán (Campeche, Quintana Roo, and Yucatán), showed the lowest percentage of "healthy" population; while Baja California and Sinaloa States showed the highest percentage of "healthy", with $28.68 \%$. None of the States has a "healthy" proportion higher than $30 \%$.

We estimated that 2,636,661 of México's population between 17 - 24 years old bear MetS (Table 5), and 9,488,508 show 1 or 2 metabolic alterations.

\section{DISCUSSION}

BMI has been used as a public health indicator, and as individual health indicator. The analysis presented here with young people of México City, shows that BMI could be used as an indicator of metabolic alteration at population level; but it fails when employed at individual level, mainly because the normal BMI-weight range $(18.5-<25.0)$ includes more than $50 \%$ of young people with metabolic alterations related to MetS. Therefore, it is not true to say that is highly probable that a person with a BMI below 25 has no metabolic alterations. However, the converse is true: it is very likely that a person with a BMI value above 25 has metabolic alterations. At individual level, and for young people, the BMI cut-off point of 25 could be used as an upper threshold of a healthy condition. However, a BMI cut-off point of 18.5 could not be used as a lower threshold of a healthy condition, because there is a subpopulation with metabolic alterations at both sides of such cut-off point.

Our finding that the normal distribution of BMI for young Mexicans runs from 19.2 to 24.0 (mean $\pm 1 \cdot \mathrm{SD}$ ), is compatible with the WHO's "normal weight" cut-off points 18.5 and 25 , only to detect the abnormal weight condition when $\mathrm{BMI}$ is out of this range, but not to define a normal condition when BMI is within the range.

Because the origins of the classification of BMI values $[2,4]$, a value above 25 needs to be understood as an indicator of a high probability to lose the healthy condition, but values under 25 are no indicators of a high probability of having a healthy condition, instead it should be understood as an indicator of "not a high probability to lose the healthy condition". This study suggests a BMI cut-off point of 22.5 to classify young Mexicans in relation to metabolic alterations, which is, in fact, lower than 25 .

Table 4. Sensitivity and specificity of BMI to MetS-related alterations. *Approximately $95 \%$ of "healthy" students have a BMI lower than $25,{ }^{* *}$ and $95 \%$ of "not healthy" students have a BMI higher than $19 ;{ }^{\dagger}$ A BMI value of 22.5 minimizes both committed and omitted errors.

\begin{tabular}{|c|c|c|c|c|c|c|c|c|c|c|}
\hline & & & & Relative & e frequencies & & Cumulated frec & quencies & Specificity & Sensitivity \\
\hline BMI & $\begin{array}{c}\text { All } \\
\text { students }\end{array}$ & "Healthy" & "Not healthy" & , "Healthy" & " "Not healthy" & " "Healthy" & "Not healthy" & $\begin{array}{l}\text { "Not healthy" (sum } \\
\text { in inverse order) }\end{array}$ & "Healthy" & "Not healthy" \\
\hline$<17.5$ & 56 & 35 & 21 & $3.4 \%$ & $0.8 \%$ & $3.4 \%$ & $0.8 \%$ & $99.2 \%$ & $3.4 \%$ & $100.0 \%$ \\
\hline 17.5 & 46 & 27 & 19 & $2.6 \%$ & $0.7 \%$ & $6.1 \%$ & $1.5 \%$ & $98.5 \%$ & $6.1 \%$ & $99.2 \%$ \\
\hline 18.0 & 58 & 31 & 27 & $3.0 \%$ & $1.0 \%$ & $9.1 \%$ & $2.5 \%$ & $97.5 \%$ & $9.1 \%$ & $98.5 \%$ \\
\hline 18.5 & 81 & 46 & 35 & $4.5 \%$ & $1.3 \%$ & $13.6 \%$ & $3.8 \%$ & $96.2 \%$ & $13.6 \%$ & $97.5 \%$ \\
\hline 19.0 & 127 & 59 & 68 & $5.8 \%$ & $2.6 \%$ & $19.4 \%$ & $6.4 \%$ & $93.6 \%$ & $19.4 \%$ & ${ }^{* *} 96.2 \%$ \\
\hline 19.5 & 121 & 66 & 55 & $6.5 \%$ & $2.1 \%$ & $25.9 \%$ & $8.5 \%$ & $91.5 \%$ & $25.9 \%$ & $93.6 \%$ \\
\hline 20.0 & 165 & 70 & 95 & $6.9 \%$ & $3.6 \%$ & $32.7 \%$ & $12.0 \%$ & $88.0 \%$ & $32.7 \%$ & $91.5 \%$ \\
\hline 20.5 & 164 & 85 & 79 & $8.3 \%$ & $3.0 \%$ & $41.0 \%$ & $15.0 \%$ & $85.0 \%$ & $41.0 \%$ & $88.0 \%$ \\
\hline 21.0 & 199 & 89 & 110 & $8.7 \%$ & $4.1 \%$ & $49.8 \%$ & $19.1 \%$ & $80.9 \%$ & $49.8 \%$ & $85.0 \%$ \\
\hline 21.5 & 201 & 76 & 125 & $7.4 \%$ & $4.7 \%$ & $57.2 \%$ & $23.8 \%$ & $76.2 \%$ & $57.2 \%$ & $80.9 \%$ \\
\hline 22.0 & 245 & 96 & 149 & $9.4 \%$ & $5.6 \%$ & $66.6 \%$ & $29.4 \%$ & $70.6 \%$ & $66.6 \%$ & $76.2 \%$ \\
\hline $22.5^{\dagger}$ & 204 & 74 & 130 & $7.2 \%$ & $4.9 \%$ & $73.8 \%$ & $34.3 \%$ & $65.7 \%$ & $73.8 \%$ & $70.6 \%$ \\
\hline 23.5 & 198 & 58 & 140 & $5.7 \%$ & $5.3 \%$ & $84.7 \%$ & $44.7 \%$ & $55.3 \%$ & $84.7 \%$ & $60.5 \%$ \\
\hline 24.0 & 194 & 45 & 149 & $4.4 \%$ & $5.6 \%$ & $89.1 \%$ & $50.3 \%$ & $49.7 \%$ & $89.1 \%$ & $55.3 \%$ \\
\hline 24.5 & 164 & 31 & 133 & $3.0 \%$ & $5.0 \%$ & $92.2 \%$ & $55.3 \%$ & $44.7 \%$ & $92.2 \%$ & $49.7 \%$ \\
\hline 25.0 & 132 & 25 & 107 & $2.4 \%$ & $4.0 \%$ & $94.6 \%$ & $59.4 \%$ & $40.6 \%$ & ${ }^{*} 94.6 \%$ & $44.7 \%$ \\
\hline 25.5 & 108 & 14 & 94 & $1.4 \%$ & $3.5 \%$ & $96.0 \%$ & $62.9 \%$ & $37.1 \%$ & $96.0 \%$ & $40.6 \%$ \\
\hline 26.0 & 117 & 14 & 103 & $1.4 \%$ & $3.9 \%$ & $97.4 \%$ & $66.8 \%$ & $33.2 \%$ & $97.4 \%$ & $37.1 \%$ \\
\hline 26.5 & 94 & 9 & 85 & $0.9 \%$ & $3.2 \%$ & $98.2 \%$ & $69.9 \%$ & $30.1 \%$ & $98.2 \%$ & $33.2 \%$ \\
\hline$\geq 27$ & 818 & 18 & 800 & $1.8 \%$ & $30.1 \%$ & $100.0 \%$ & $100.0 \%$ & $0.0 \%$ & $100.0 \%$ & $30.1 \%$ \\
\hline Total students & 3683 & 1021 & 2662 & & & & & & & \\
\hline
\end{tabular}


Table 5. Prevalence of MetS in States of México. The prevalence was calculated based on BMI range (Table 2), applied to the structure of BMI ranges by State obtained from ENSANUT 2006 [14]. *Estimated population based on national population counting [15], age structure [16], and a mortality rate of 76.11 deaths per 100,000 individuals per year from 2006 to 2010 [17].

\begin{tabular}{|c|c|c|c|c|c|c|}
\hline \multirow[b]{2}{*}{ México State } & \multirow[b]{2}{*}{ "Healthy" } & \multicolumn{2}{|c|}{ Estimated prevalence } & \multicolumn{3}{|c|}{ Population } \\
\hline & & "With 1 or 2 alterations" & "With MetS" & $17-24$ years old ${ }^{*}$ & "With 1 or 2 alterations" & "With MetS" \\
\hline Chiapas & $28.57 \%$ & $57.24 \%$ & $14.19 \%$ & 176,251 & 100,879 & 25,013 \\
\hline Oaxaca & $28.33 \%$ & $57.30 \%$ & $14.36 \%$ & 403,141 & 231,013 & 57,906 \\
\hline Guerrero & $28.22 \%$ & $57.33 \%$ & $14.45 \%$ & 72,260 & 41,423 & 10,439 \\
\hline Hidalgo & $27.68 \%$ & $57.76 \%$ & $14.55 \%$ & 127,415 & 73,598 & 18,540 \\
\hline Baja California & $28.68 \%$ & $56.74 \%$ & $14.58 \%$ & 383,145 & 217,381 & 55,880 \\
\hline Sinaloa & $28.68 \%$ & $56.63 \%$ & $14.69 \%$ & 90,241 & 51,101 & 13,255 \\
\hline Puebla & $27.44 \%$ & $57.79 \%$ & $14.76 \%$ & 795,548 & 459,736 & 117,457 \\
\hline Aguascalientes & $28.13 \%$ & $57.02 \%$ & $14.84 \%$ & 484,440 & 276,251 & 71,882 \\
\hline Nayarit & $28.00 \%$ & $56.97 \%$ & $15.02 \%$ & $1,159,313$ & 660,503 & 174,127 \\
\hline Jalisco & $28.28 \%$ & $56.61 \%$ & $15.10 \%$ & 257,778 & 145,927 & 38,936 \\
\hline Zacatecas & $28.14 \%$ & $56.66 \%$ & $15.20 \%$ & 842,371 & 477,274 & 128,000 \\
\hline Tlaxcala & $26.62 \%$ & $57.83 \%$ & $15.54 \%$ & 566,314 & 327,505 & 88,016 \\
\hline Durango & $26.82 \%$ & $57.61 \%$ & $15.57 \%$ & 396,512 & 228,428 & 61,740 \\
\hline Querétaro & $26.97 \%$ & $57.45 \%$ & $15.58 \%$ & $1,071,138$ & 615,407 & 166,835 \\
\hline Veracruz & $26.79 \%$ & $57.55 \%$ & $15.66 \%$ & $2,146,396$ & $1,235,255$ & 336,096 \\
\hline Morelos & $27.08 \%$ & $57.22 \%$ & $15.70 \%$ & 699,824 & 400,409 & 109,857 \\
\hline San Luis Potosí & $27.21 \%$ & $57.08 \%$ & $15.70 \%$ & 255,368 & 145,776 & 40,095 \\
\hline Coahuila & $27.54 \%$ & $56.60 \%$ & $15.85 \%$ & 157,880 & 89,357 & 25,030 \\
\hline Michoacán & $26.75 \%$ & $57.19 \%$ & $16.06 \%$ & 597,616 & 341,760 & 95,954 \\
\hline Guanajuato & $26.00 \%$ & $57.63 \%$ & $16.37 \%$ & 628,921 & 362,418 & 102,941 \\
\hline Chihuahua & $26.73 \%$ & $56.80 \%$ & $16.46 \%$ & 910,346 & 517,056 & 149,866 \\
\hline Colima & $26.22 \%$ & $57.26 \%$ & $16.52 \%$ & 269,424 & 154,269 & 44,507 \\
\hline Baja California Sur & $26.23 \%$ & $57.16 \%$ & $16.60 \%$ & 164,758 & 94,176 & 27,354 \\
\hline Nuevo León & $26.39 \%$ & $56.89 \%$ & $16.71 \%$ & 417,374 & 237,449 & 69,759 \\
\hline Tabasco & $25.43 \%$ & $57.76 \%$ & $16.81 \%$ & 417,190 & 240,953 & 70,125 \\
\hline Distrito Federal & $25.09 \%$ & $57.76 \%$ & $17.14 \%$ & 362,461 & 209,349 & 62,139 \\
\hline Tamaulipas & $25.44 \%$ & $57.41 \%$ & $17.14 \%$ & 343,627 & 197,276 & 58,913 \\
\hline Sonora & $25.58 \%$ & $57.25 \%$ & $17.17 \%$ & 440,275 & 252,045 & 75,606 \\
\hline Yucatán & $23.91 \%$ & $58.28 \%$ & $17.81 \%$ & 180,617 & 105,268 & 32,161 \\
\hline Campeche & $24.03 \%$ & $58.14 \%$ & $17.82 \%$ & $1,189,540$ & 691,653 & 212,015 \\
\hline Estado de México & $24.49 \%$ & $57.51 \%$ & $18.00 \%$ & 291,504 & 167,637 & 52,470 \\
\hline Quintana Roo & $23.48 \%$ & $58.30 \%$ & $18.22 \%$ & 240,118 & 139,976 & 43,747 \\
\hline MÉXICO & $26.71 \%$ & $57.34 \%$ & $15.94 \%$ & $16,539,106$ & $9,488,508$ & $2,636,661$ \\
\hline
\end{tabular}




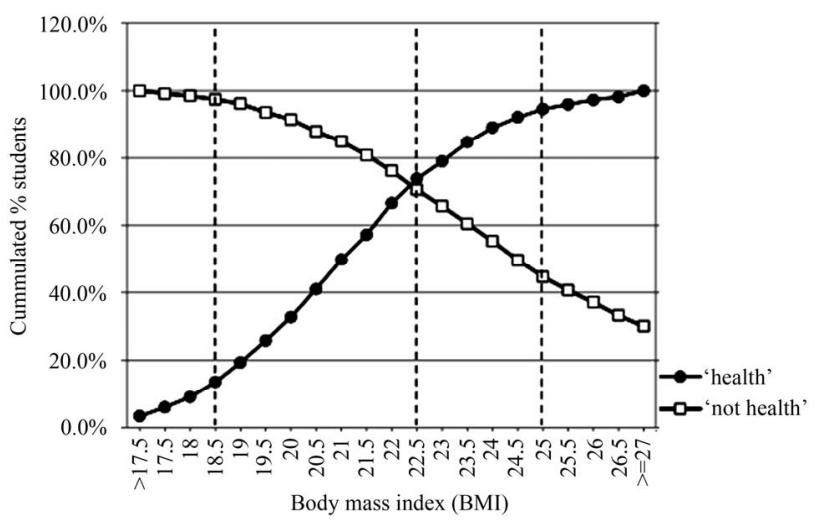

Figure 2. Sensitivity and specificity of BMI to MetS-related alterations. Dashed vertical lines indicate BMI cut-off points to detect, 1) the $95 \%$ of "not healthy" students ( $\geq 18.5) ; 2)$ the $95 \%$ of "healthy" students $(\leq 25.0) ; 3)$ optimal minimizing both, committed and omitted errors (22.5).

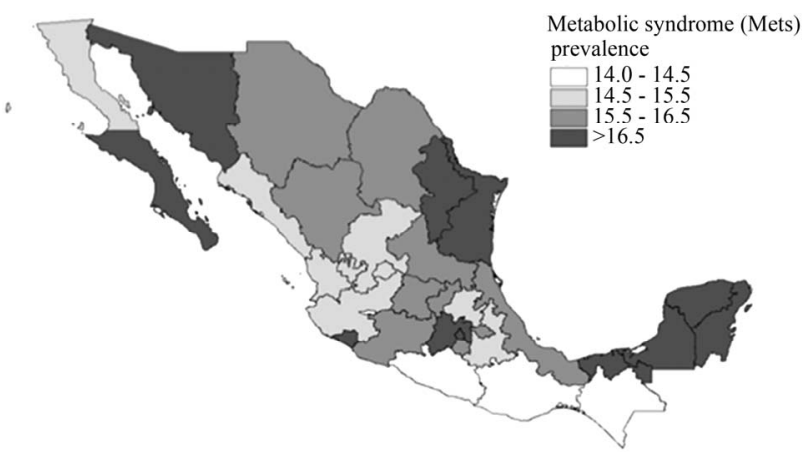

Figure 3. Metabolic syndrome prevalence in México by State.

The ENSANUT 2006 [14] is a valuable database to make estimations at State and nation levels; nevertheless, we detected a bias in the sampling, mainly because a bimodal-shaped curve when histograms for BMI ranges by unit is built. For that reason, we decided to use the prevalence of MetS in WHO classes (Table 2) instead of prevalence by BMI unit ranges (Figure 1 and Table 3). We suspect that MetS prevalence calculated here is overestimated, since ENSANUT is most probably biased due to participation of not healthy people. México's MetS map (Figure 3) shows a qualitative comparison between states, but more studies are needed to confirm or modify these results with more reliable data.

In conclusion, the BMI of healthy young México City inhabitants (17 - 24 years old) shows a normal distribution pattern that runs mainly from 19 to 24 , with a mean of 21.6 and standard deviation of 2.4. The BMI of all young México City inhabitants, including "healthy" and "not healthy" persons is biased to the right, reflecting the high prevalence of obesity $($ mean $=24.2, \mathrm{SD}=4.3)$. The BMI could be used as a public health tool to estimate or classify how healthy a young population is regarding metabolic alterations. However, at individual level BMI fails showing inadequate sensitivity and specificity for cut-off points for "normal weight", in the context of MetS-related alterations. The "normal weight" upper cut-off point of 25 is better applied if individuals exclude the possibility of a normal weight condition when BMI crosses this limit. We suggest that BMI of 22.5 is a public health tool useful to classify the population into "healthy" and "not healthy". The estimated MetS prevalence for México, applying the method proposed is $15.95 \%$. The Peninsula of Yucatán States (Campeche, Quintana Roo, and Yucatán) and the State of México present the higher MetS prevalence in young Mexicans (17 - 24 years old), while the South-West States (Chiapas, Guerrero, and Oaxaca) present the lower MetS prevalence. A total of 2,636,661 young people in México are estimated to present MetS.

\section{ACKNOWLEDGEMENTS}

This work was supported in part by grants PAPIIT IN226708, PAPIME PE204707, PAPIME PE303507, PAPCA 2008-2009, from U.N.A.M.; PICDS08-69 from ICyT-GDF. Authors are indebted to CARPERMOR, S.A. de C.V., and Universidad Autónoma de la Ciudad de México.

\section{REFERENCES}

[1] World Health Organization (2000) Obesity: Preventing and managing the global epidemic. Report of a WHO Consultation. World Health Organization Technical Report, Series 894, 1-253.

[2] World Health Organization (1995) Physical status: The use and interpretation of anthropometry. Report of a WHO Expert Committee. World Health Organization Technical Report, Series 854, 1-452.

[3] World Health Organization (2011) Global Database on Body Mass Index. An interactive surveillance tool for monitoring nutrition transition. http://apps.who.int/bmi

[4] World Health Organization (1986) Use and interpretation of anthropometric indicators of nutritional status. Bulletin World Health Organization, 64, 929-941.

[5] Seidell, J.C. (2000) Obesity, insulin resistance and diabetes-A worldwide epidemic. British Journal of Nutrition, 83, S6-S8. doi:10.1017/S000711450000088X

[6] Popkin, B.M. and Gordon-Larsen, P. (2004) The nutrition transition: Worldwide obesity dynamics and their determinants. International Journal of Obesity, 28, S2-S9. doi:10.1038/sj.ijo.0802804

[7] James, W.P. (2008) The epidemiology of obesity: The size of the problem. Journal of Internal Medicine, 263, 336-352. doi:10.1111/j.1365-2796.2008.01922.x

[8] Low, S., Chin, M.C. and Deurenberg-Yap, M. (2009) Review on epidemic of obesity. Annals of the Academy of Medicine Singapore, 38, 57-59.

[9] Cole, T.J., Bellizzi, M.C., Flegal, K.M., et al. (2000) Establishing a standard definition for child overweight and obesity worldwide: International survey. British Medical Journal, 320, 1240-1243.

doi:10.1136/bmj.320.7244.1240 
[10] Onis, M. (2006) WHO Child Growth Standards based on length/heigth, weight and age. Acta Paediatrica Supplement, 450, 76-85.

[11] Ezzati, M., Lopez, A.D., Rodgers, A., et al. (2002) Comparative Risk Assessment Collaborating Group: Selected major risk factors and global and regional burden of disease. Lancet, 360, 1347-1360. doi:10.1016/S0140-6736(02)11403-6

[12] Alberti, K.G., Eckel, R.H., Grundy, S.M., et al. (2009) Harmonizing the metabolic syndrome. A Joint Interim Statement of the International Diabetes Federation Task Force on Epidemiology and Prevention; National Heart, Lung, and Blood Institute; American Heart Association; World Heart Federation; International Atherosclerosis Society; and International Association for the Study of Obesity. Circulation, 120, 1640-1645. doi: 10.1161/CIRCULATIONAHA.109.192644

[13] Grundy, S.M., Cleeman, J.I., Daniels, S.R., et al. (2005) Diagnosis and management of the metabolic syndrome. An American Heart Association/National Heart, Lung, and Blood Institute Scientific Statement. Circulation, 112, 2735-2752.

doi:10.1161/CIRCULATIONAHA.105.169404
[14] Secretaría de Salud (2010) Encuesta Nacional Salud y Nutrición 2006 (ENSANUT 2006). Instituto Nacional de Salud Pública (INSP), Secretaría de Salud. Gobierno de México.

http://www.insp.mx/encuesta-nacional-salud-y-nutricion2006.html

[15] INEGI (2010) Conteo de Población y Vivienda 2005. Instituto Nacional de Estadística, Geografía e Informática, México.

http://www.inegi.org.mx/est/contenidos/proyectos/ccpv/c pv2005

[16] INEGI (2010) Muestra del II Conteo de Población 2005. Microdatos. Instituto Nacional de Estadística, Geografía e Informática, México.

http://www.inegi.org.mx/est/contenidos/espanol/soc/sis/m icrodatos

[17] Secretaría de Salud (2010) SINAIS: Tasa de mortalidad (estandarizada por edad) por grandes grupos de causas, según sexo y entidad federativa de residencia habitual. Sistema Nacional de Información en Salud (SINAIS). Secretaría de Salud, México. http://www.sinais.salud.gob.mx/mortalidad 